\title{
Factors Affecting the Ovilarval Density of Aedes Spp. Mosquitoes in Selected Rice Fields of Muňoz, Nueva Ecija
}

\author{
Jerome Cadiente Soriano and Clarissa Yvonne Jueco-Domingo \\ College of Veterinary Science \& Medicine, Central Luzon State University, Nueva Ecija 3120, Philippines
}

\begin{abstract}
Variables among the macroclimate, microclimate and rice canopy categories and three other different farming systems were evaluated on their effects to the egg and larval density of Aedes spp. mosquitoes known as transmitters of animal and human diseases. No statistical difference in egg density (\#eggs $/ \mathrm{mL})$ among farming systems $(\mathrm{P}=0.345)$ were observed. However, there was significant difference in larval density (\#larvae/mL) among farming systems $(\mathrm{P}<0.001)$ particularly between organic and conventional farms and between organic and mixed farms at $(\mathrm{P}<0.05)$. Among the variables in the macroclimate category, wind velocity and ambient temperature significantly influenced larval density in conventional farms. Among the variables in the microclimate category, water temperature significantly contributed to larval density in both the mixed and conventional farms whereas water turbidity, in conventional farms. Among the variables in the rice canopy category, the number of tillers per plant was a significant contributor to larval density in all farm types. No variable among the environmental exposure categories affected the larval density in organic farms.
\end{abstract}

Key words: Mosquito larval control, farming system, ovilarval density, organic farming, Aedes Spp. Mosquito.

\section{Introduction}

Mosquitoes serve as transmitters of human and animal diseases. The increasing trend of mosquito borne diseases remains a challenge to national and international health agencies to implement strategies to control it. Some of the known diseases are yellow fever, encephalitis, dengue, and dirofilariasis, fowl pox [1].

Vector control is an important strategy known to enhance the sustainability of high drug coverage. It helps interrupt transmission in combination with mass drug administration particularly in high risk, peri-urban areas and prevent-re-establishment of transmission in vulnerable areas [2].

From the global standpoint, approximately 140 million hectares of land are annually devoted to rice cultivation. Because the rice fields are flood on a semi-permanent basis during each growing season,

Corresponding author: Clarissa Yvonne Jueco-Domingo, Ph.D., main research field: parasitology. they provide ideal breeding habitat for a number of potential vectors of vector borne diseases [3].

Natural environment such as the interaction between temperature, rainfall or variations in daily microclimates may be important determinants in density of eggs and larvae of mosquitoes in breeding sites. These are very important factors in the identification of key vector-breeding sites and the reason is they are mosquito productive.

By determining environmental factors that influence density of eggs and larvae of Aedes spp. mosquitoes in three different rice farm systems in the Science City of Muñoz Nueva Ecija namely, pure organic, mixed and conventional farming, farmers could be advised to be on the look out for the density of mosquito eggs and larvae in order to make them responsible for adopting modified human behaviors that would protect them, their family and even their livestock reared around their farms against the bites of mosquitoes. 
Hence, the study determined the presence of association between environmental factors together with the different rice farm systems being adopted by rice farmers in the Science City of Muñoz, Nueva Ecija and the egg and larval density of Aedes spp. of mosquitoes. Specifically, the study determined whether the following environmental factors affected the egg and larval density of Aedes spp. mosquito: (1) types of farming systems namely organic, mixed and conventional farms; (2) macroclimate factors such as rainfall, humidity, ambient temperature and wind velocity; (3) microclimate factors such as water temperature, water $\mathrm{pH}$ and water turbidity; and (4) rice canopy factors such as rice height $(\mathrm{cm})$, number of tillers per rice plant and number of panicles per rice plant. Likewise, the study predicted egg and larval densities of Aedes spp. mosquitoes using multiple logistic regression models computed from environmental factors found to be effect modifiers at $(p<0.05)$.

\section{Material and Methods}

\subsection{Identification and Collection of Samples}

Three organic, three mixed and three conventional rice farms were identified within the Science City of Munoz, Nueva Ecija for sampling collection through the assistance of the Philippine Rural Reconstruction Movement farmers' cooperative. External in puts such as herbicides, fertilizers and pesticides applied on the rice fields by farmers were noted.

Evaluation of rice plants and collection of water samples with mosquito eggs and larvae were done from three different sites of each rice field as replicates. Duration of collection period for the entire study was two months with weekly collections for a total of eight (8) collections.

\subsection{Gathering of Macroclimate Variables}

Macroclimate variables include meteorological factors such as ambient temperature $\left({ }^{\circ} \mathrm{C}\right)$, humidity (\%), wind velocity (mps) and rainfall (mm). They were taken from the Agrometeorological office of the
Dept. of Agronomy, Philippine Rice Research Institute in Maligaya, Science City of Munoz and Nueva Ecija.

\subsection{Gathering of Characteristics of Rice Paddy Water}

Around fifty (50) milliliters (mL) of water from the rice paddies were collected and placed in clean properly labeled plastic bottles. Samples from the water were submitted for $\mathrm{pH}$ and water turbidity analysis at the Philippine Rice Institute Department of Agronomy. The $\mathrm{pH}$ was measured using a $\mathrm{pH}$ meter while the water turbidity was analyzed using spectrophotometric measurement for light absorbance (nanometer). Water temperature was measured from all sample sites using the Field Environmental Thermometer.

\subsection{Evaluation of Rice Canopy Development}

All rice plants within the area of one by one square meter, also designated for collection site of water sample, which was evaluated for rice canopy factors:

1. Plant height in centimeters $(\mathrm{cm})$-taken from the base of the plant which was submerged in water until the highest tip of the plant. A meter stick was used for measuring;

2. Number of tillers per plant-number of culmns or tillers was counted per plant and the mean per sampling site was recorded;

3. Number of panicles per plant-number of panicles was counted per plant and the mean per sampling site was recorded.

\subsection{Identification \& Counting of Eggs and Larvae of Aedes spp. Mosquitoes}

Three (3) different collection sites for each type of rice farm were sampled for water to determine the number of eggs and larvae. Each site was marked with a flag to identify the area for collection throughout the study period.

Around $240 \mathrm{~mL}$ of water with eggs and larvae was collected from each replicate site and placed in 
chemically clean bottles. An aliquot of ten $10 \mathrm{~mL}$ was transferred to a vial and a thin layer of mineral oil was placed over the surface of the water sample to suffocate the larvae. After the larvae have been killed, the entire contents of the vial were poured into a Petri dish and the eggs and larvae were counted using magnifying lens.

Only Aedes spp. mosquito eggs that were laid singly and did not have lateral floats were counted. The larvae that hanged diagonally from the water surface were assumed to be Aedes spp. Although Culex spp. also has larvae that hang diagonally from the water surface, the females prefer to lay eggs in stagnant, dirty water as compared to Aedes spp. that lay eggs in rice paddies.

Egg density per milliliter was computed by number of eggs counted divided by $10 \mathrm{~mL}$ while larval density per $\mathrm{mL}$ was measured by the number of larvae counted divided by $10 \mathrm{~mL}$. Values of the egg and larval densities were transmuted according to the area of the entire rice field.

\subsection{Data Analysis}

Mean scores of the replicates of each rice farm were computed. One-way analysis of variance was used to evaluate the significant difference of the different environmental exposure variables by farm and the significant difference of mean egg and larval densities by farm.

Multivariate analysis was done to assess the association of exposure variables grouped in categories or as individual entity to the mean egg density or mean larval density. Each category, for instance, macroclimate, microclimate and plant canopy was forced into a multiple logistic regression model. A regression model per category was created which served as the main effects model. Each exposure variable under that category was assessed on how it interacted to the main effects model. The category which had a log likelihood ratio p-value of less than 0.05 was considered an effect measure modifier. Hence, it could significantly modify either the mean egg density or the mean larval density.

Similarly, individual exposure variables were subjected to multivariate analysis to assess their association to the mean egg density or mean larval density. Each exposure variable was forced into a multiple logistic regression model. An exposure variable which had a log likelihood ratio p-value of less than 0.05 was considered an effect measure modifier, hence, it could significantly modify either the mean egg density or the mean larval density.

\section{Results and Discussion}

Comparing the summation of the mean egg density (\#eggs/mL) and larval density in organic, mixed and conventional farms, ANOVA showed no significant difference at $(p=0.345)$ in the egg density while larval density was significantly different among the farming systems at $(\mathrm{p}<0.001)$ (Table 1$)$. This implies that the water paddies in mixed and conventional farms are better culture grounds for sustaining larval development. On the other hand, water paddies of organic farms are least attractive for sustaining larval density.

Likewise, results imply that egg density is not a good monitoring index for mosquito density in evaluating strategies for integrated vector control management program since there is no difference in the density among farms despite of a significant difference in the larval density. Hence, between egg and larval density, the latter is more sensitive as environmental index for monitoring mosquito density.

Table 1 Analysis of variance of the summation of the mean egg and larval density by farming system.

\begin{tabular}{lll}
\hline & $\begin{array}{l}\text { Egg density } \\
(\text { No.eggs/mL) }\end{array}$ & $\begin{array}{l}\text { Larval density } \\
(\text { No.larva/mL) }\end{array}$ \\
\hline Organic & $1,730^{\mathrm{a}}$ & $2,711^{\mathrm{a}}$ \\
Mixed & $2,093^{\mathrm{a}}$ & $5,229^{\mathrm{b}}$ \\
Conventional & $2,651^{\mathrm{a}}$ & $7,590^{\mathrm{c}}$ \\
P value & $0.345^{\mathrm{ns}}$ & $0.000^{* *}$ \\
\hline * ns-not significant $($ similar superscripts are not significantly \\
different); \\
** highly significant.
\end{tabular}



Selected Rice Fields of Muňoz, Nueva Ecija

Table 2 shows the crude analysis of environmental exposure categories by farm type to identify which one would be an effect modifier $(\mathrm{p}<0.05)$ to egg density of Aedes spp. Macroclimate variables include the ambient temperature $\left({ }^{\circ} \mathrm{C}\right)$, humidity (\%), wind velocity (mps) and rainfall (mm). Results showed that only the macroclimate had a moderate modifying effect at $\mathrm{p}=0.05$ to egg density in organic farms. In the case of mixed farms, no environmental exposure category had any association with egg density while the microclimate category had a modifying effect at $\mathrm{p}=0.002$ to egg density in conventional farms. Microclimate variables include those which characterize the water quality of the rice paddies such as water $\mathrm{pH}$, water temperature and water turbidity.

When taken individually (Table 3), the wind was a significant contributor under the macroclimate category at $\mathrm{p}=0.031$ in organic farms while it was the ambient temperature at $\mathrm{p}=0.008$ in conventional farms. The water temperature under the microclimate category was a significant contributor to egg density at $\mathrm{p}=0.019$ in mixed farms and $\mathrm{p}=0.000$ in conventional farms.

Table 4 shows the crude analysis of environmental exposure categories by farm type to identify which one would be an effect modifier $(\mathrm{p}<0.05)$ to larval density of Aedes spp. Results showed that no environmental exposure category had a modifying effect to larval density in organic farms. However, the microclimate category was an effect modifier at $\mathrm{p}=$ 0.031 in mixed farms whereas all environmental exposure categories were effect modifiers to larval density in conventional farms.

Table 2 Multivariate analysis of environmental exposure categories by farm type against egg density of Aedes spp.

\begin{tabular}{llll}
\hline & Organic farm & Mixed farm & Conventional farm \\
\hline Macroclimate & $0.05^{*}$ & 0.123 & 0.057 \\
Microclimate & 0.561 & 0.109 & $0.002^{* *}$ \\
Plant canopy & 0.679 & 0.116 & 0.488 \\
\hline
\end{tabular}

*significant;

**highly significant.

Table 3 Significant exposure variables to mean Egg Density (ED).

\begin{tabular}{llll}
\hline & \multicolumn{2}{l}{-Value $<0.05$ (effect modifier) } & Conventional farms \\
\cline { 2 - 4 } & Organic farms & Mixed farms & 0.057 \\
\hline Macroclimate category & 0.05 & 0.123 & 0.782 \\
Wind (mps) & $0.031^{*}$ & 0.134 & 0.600 \\
Rainfall (mm) & 0.730 & 0.096 & 0.633 \\
Humidity (\%) & 0.203 & 0.060 & $0.008^{*}$ \\
Ambient temp. $\left({ }^{\circ} \mathrm{C}\right)$ & 0.561 & 0.850 & $0.002^{*}$ \\
Microclimate category & 0.561 & 0.109 & 0.760 \\
Water pH & 0.953 & 0.293 & $0.000^{*}$ \\
Water temp. $\left({ }^{\circ} \mathrm{C}\right)$ & 0.304 & $0.019 *$ & 0.251 \\
Water turbidity (nm) & 0.447 & 0.604 & 0.488 \\
Rice canopy category & 0.679 & 0.116 & 0.442 \\
Plant height (cm) & 0.414 & 0.678 & 0.406 \\
No. of tillers/plant & 0.401 & 0.442 & 0.395 \\
No. of panicles/plant & 0.418 & n.a. &
\end{tabular}

* na-not applicable;

*statistically significant. 

Selected Rice Fields of Muňoz, Nueva Ecija

Table 4 Multivariate analysis of environmental exposure variables by farm type against larval density of Aedes spp.

\begin{tabular}{llll}
\hline & Organic farm & Mixed farm & Conventional farm \\
\hline Macroclimate & 0.342 & 0.511 & $0.000^{* *}$ \\
Microclimate & 0.302 & $0.031^{* *}$ & $0.000^{* *}$ \\
Plant canopy & 0.059 & 0.054 & $0.000^{* *}$ \\
\hline
\end{tabular}

*significant;

**highly significant.

When taken individually (Table 5), the wind velocity and ambient temperature strongly contributed to the macroclimate category in affecting the larval density in conventional farms at $\mathrm{p}=0.030$ and $\mathrm{p}=0.004$ respectively. Water temperature and water turbidity strongly contributed to the microclimate category in affecting the larval density in conventional farms at $\mathrm{p}$ $=0.000$ and $\mathrm{p}=0.019$ respectively. Finally, the number of tillers per plant strongly contributed to rice canopy category in affecting the larval density in conventional farms at $\mathrm{p}=0.04$. Rice canopy indicators include plant height $(\mathrm{cm})$, the number of tillers per plant and number of panicles per plant.

Table 6 shows the analysis of variance of the mean values of individual exposure variables by farm type. Water temperature, water $\mathrm{pH}$, number of tillers and panicles per rice plant significantly differed by farm system whereas, water turbidity and plant height were not significantly different at $\mathrm{p}=0.115$ and $\mathrm{p}=0.766$ respectively, significantly by farm type.

Table 5 Significant exposure variables to mean Larval Density (LD).

\begin{tabular}{llll}
\hline & \multicolumn{2}{l}{$\mathrm{p}$-value $<0.05$ (effect modifier) } & \\
\cline { 2 - 4 } & Organic farms & Mixed farms & Conventional farms \\
\hline Macroclimate category & 0.342 & 0.511 & $0.000^{*}$ \\
Wind (mps) & 0.249 & 0.111 & $0.030^{*}$ \\
Rainfall (mm) & 0.164 & 0.293 & 0.078 \\
Humidity (\%) & 0.426 & 0.233 & 0.126 \\
Ambient temp. $\left({ }^{\circ} \mathrm{C}\right)$ & 0.376 & 0.939 & $0.004^{*}$ \\
Microclimate category & 0.302 & $0.031^{*}$ & $0.000^{*}$ \\
Water pH & 0.065 & 0.228 & 0.997 \\
Water temp. $\left({ }^{\circ} \mathrm{C}\right)$ & 0.477 & 0.057 & $0.000^{*}$ \\
Water turbidity (nm) & 0.878 & 0.211 & $0.019^{*}$ \\
Rice canopy category & 0.059 & 0.054 & $0.000^{*}$ \\
Rice plant height & 0.374 & 0.953 & 0.565 \\
No. of tillers/plant & 0.158 & 0.646 & $0.04^{*}$ \\
No.of panicles/plant & 0.064 & n.a. & n.a. \\
\hline
\end{tabular}

* na-not applicable;

*statistically significant

Table 6 Comparison of mean values of environmental exposure variables by farm systems.

\begin{tabular}{lllll}
\hline & Organic farms & Mixed farms & Conventional farms & p-value \\
\hline Mean $\mathrm{H}_{2} \mathrm{O}$ temp. $\left(\mathrm{T}^{0}\right)$ & 33.87 & 34.46 & 34.83 & $0.002^{* *}$ \\
Mean $\mathrm{H}_{2} \mathrm{O}$ pH & 7.790 & 7.754 & 7.521 & $0.002^{* *}$ \\
Mean $\mathrm{H}_{2} \mathrm{O}$ turbidity & 88.58 & 90.514 & 91.162 & $0.115^{\mathrm{ns}}$ \\
Mean rice ht. (cm) & 34.26 & 35.37 & 35.65 & $0.766^{\mathrm{ns}}$ \\
Mean no. of tillers/plant & 33.00 & 27.97 & 29.45 & $0.002^{* *}$ \\
Mean no. of panicles/plant & 296 & 293 & 341 & $0.04^{* *}$ \\
\hline
\end{tabular}

* ns-not significant;

** means highly significant. 
Multiple logistic regression models were created to predict larval density using all the environmental exposure variables that were identified as effect modifiers at $\mathrm{p}<0.05$. Since majority of the environmental exposure variables strongly modified larval density than egg density (Tables 3 and 5), only prediction equations for larval density were computed.

\section{Mixed Farms}

Estimated equation for larval density = $-41,881+525\left(\mathrm{H}_{2} \mathrm{O}\right.$ (Temp.))

$+2,161\left(\mathrm{H}_{2} \mathrm{O}(\mathrm{pH})\right)$

$+129 \mathrm{H}_{2} \mathrm{O}$ (Turbid.)

Estimated equation for larval density $=$ 10,771 - 20 (Rice Ht) - 231(Rice Tillers)

\section{Conventional Farms}

Estimated equation for larval density = $-2,805$ - 580(Rainfall) - 449(Humidity)

+ 1,983(Wind) + 1,467(Temp.)

Estimated equation for larval density $=$ $-134,062+3426\left(\mathrm{H}_{2} \mathrm{O}\right.$ (Temp.))

$+8\left(\mathrm{H}_{2} \mathrm{O}(\mathrm{pH})\right)$

$+240\left(\mathrm{H}_{2} \mathrm{O}\right.$ (Turbid.))

Estimated equation for larval density $=$ 21,824 - 98 (Rice ht.) - 479 (Rice tillers)

From results of the study, the implications are herein presented.

\subsection{Macroclimate Category}

In general, the macroclimate category was not significantly associated with egg density in all farm systems since the collection period was made during rainy season with no significant differences in macroclimate variables across the different farms based on location and replication site $(\mathrm{p}>0.05)$. Thus, the macroclimate category did not produce a significant difference in its effect on the egg density among the different farm systems. On the other hand, it was significantly modified the larval density in conventional farms.
Wind velocity was found to be a significant contributor to this category. Wind affects the survival of mosquitoes which sustains disease transmission. A gentle breeze facilitates a flight range of 10 meters. The flight range for females is usually longer than males and some have been recorded as far as 75 miles from their breeding source [4]. Aedes spp. mosquitoes vary with species and some are reported to migrate many miles from their aquatic larval habitat.

Similarly, ambient temperature was also seen as a contributor. Environmental temperature is essential in hastening the maturity of female mosquitoes to breed and lay eggs and in hastening the hatching of eggs to larvae [5].

\subsection{Microclimate Category}

In general, the microclimate category was significantly associated and effectively modified the egg density in conventional farms and larval density in mixed and conventional farms. Variables under the microclimate category are those which characterize the water quality of the rice paddies. External inputs in mixed and conventional farms could have affected the water quality that significantly influenced egg and larval densities in these farm systems [6].

Water temperature in mixed and conventional farms was found to be significantly warmer $\left(34.46{ }^{\circ} \mathrm{C}\right.$ and $34.83{ }^{\circ} \mathrm{C}$, respectively) than in organic farms. Studies have observed that female mosquitoes are more attracted to warm temperatures. Since water is the preferred breeding and egg laying site of mosquitoes these could be the reason why more eggs were oviposited in conventional farms. Similarly, mosquito larvae must live in water from 7 days to 14 days depending on water temperature. Since larval density was significantly different among the three farm systems and microclimate variables with water temperature being a significant contributor, significantly modified larval density in mixed and conventional farms, this could imply that both farms were very conducive in sustaining the lifespan of the 
larvae.

Table 7 Summary of regression analysis on larval density in mixed farms based on microclimate variables.

\begin{tabular}{|c|c|c|c|c|}
\hline Predictor & Coef. & $\begin{array}{l}\text { St } \\
\text { Dev. }\end{array}$ & T-stat & $\begin{array}{l}\mathrm{P} \\
\text { value }\end{array}$ \\
\hline Constant & $-41,881$ & 16,904 & -2.48 & 0.019 \\
\hline $\mathrm{H}_{2} \mathrm{O}$ temp. & 525.2 & 265.8 & 1.98 & 0.057 \\
\hline $\mathrm{H}_{2} \mathrm{O} \mathrm{pH}$ & 2,161 & 1,757 & 1.23 & 0.228 \\
\hline $\mathrm{H}_{2} \mathrm{O}$ turbidity & 129.0 & 100.9 & 1.28 & 0.211 \\
\hline
\end{tabular}

* S = 3,570; R-Sq = 24.6\%; R-Sq (adj) = 7.4\%.

Table 8 Summary of regression analysis on larval density in mixed farms based on rice canopy variables.

\begin{tabular}{lllll}
\hline Predictor & Coef. & St & T-stat & P \\
& Dev. & 2,815 & 3.83 & value \\
\hline Constant & 10,771 & 343.8 & -0.06 & 0.001 \\
Rice Ht & -20.3 & 498.7 & -0.46 & 0.953 \\
Rice Till & -231.4 & & 0.646 \\
\hline
\end{tabular}

* S = 3,694; R-Sq = 16.7\%; R-Sq (adj) = 11.5\%.

Table 9 Summary of regression analysis on larval density in conventional farms based on macroclimate variables.

\begin{tabular}{lllll}
\hline Predictor & Coef. & St & T-stat & $\begin{array}{l}\text { P } \\
\text { value }\end{array}$ \\
\hline Constant & -2805 & 36,960 & -0.08 & 0.940 \\
Rainfall & -580.3 & 319.8 & -1.81 & 0.078 \\
Humidity & -448.7 & 285.9 & -1.57 & 0.126 \\
Wind velocity & $1,983.3$ & 877.6 & 2.26 & 0.030 \\
Ambient temp. & $1,467.3$ & 477.6 & 3.07 & 0.004 \\
\hline
\end{tabular}

* S = 4,024; R-Sq = 51.7\%; R-Sq (adj) = 46.0\%.

Table 10 Summary of regression analysis on larval density in conventional farms based on miroclimate variables.

\begin{tabular}{|c|c|c|c|c|}
\hline Predictor & Coef. & $\begin{array}{l}\text { St } \\
\text { Dev. }\end{array}$ & T-stat & $\begin{array}{l}\mathrm{P} \\
\text { value }\end{array}$ \\
\hline Constant & $-134,062$ & 25,811 & -5.19 & 0.000 \\
\hline $\mathrm{H}_{2} \mathrm{O}$ Temp & $3,426.0$ & 461.0 & 7.43 & 0.000 \\
\hline $\mathrm{H}_{2} \mathrm{O} \mathrm{pH}$ & 8 & 1,939 & 0.00 & 0.997 \\
\hline $\mathrm{H}_{2} \mathrm{O}$ Turbidity & 240.36 & 98.01 & 2.45 & 0.019 \\
\hline
\end{tabular}

* S = 3,203; R-Sq = 68.5\%; R-Sq (adj) = 65.8\%.

Table 11 Summary of regression analysis on larval density in conventional farms based on microclimate variables.

\begin{tabular}{lllll}
\hline Predictor & Coef. & St & T-stat & P \\
& & Dev. & value \\
\hline Constant & 21,824 & 1,612 & 13.54 & 0.000 \\
Rice Ht & -97.9 & 168.8 & -0.58 & 0.565 \\
Rice Till & -479.4 & 225.0 & -2.13 & 0.040 \\
\hline
\end{tabular}

*S = 2,993; R-Sq = 71.7\%; R-Sq (adj) = 70.1\%.

Water turbidity was found to significantly modify the larval density in conventional farms. Water turbidity is a consequence of fertilizer application. Fertilizers contain nitrogen, phosphorus and potassium [7]. Microorganisms in the soil decompose them in order to release the nutrients needed by the plants. Sources of organic fertilizers are green manure composed of decaying vegetation, crop residue or rice straw and animal manure. It takes three days for green manure to be decomposed, one month for crop residue 
and one week for animal manure. Whereas, inorganic fertilizers were being used in conventional farms take two to three weeks. In this study, fertilizers used by organic farms were processed poultry manure while mixed and conventional farms utilized inorganic fertilizer (registered brand name "Crop Giant 15-15-30”) [7].

Water samples were analyzed for the presence of microscopic organisms. Results revealed the presence of filamentous green algae such as Oedogonium, Microspora and Zygnemopsis. Simple blue-green algae and filamentous blue-green algae were also found such as Rivularia and Oscillatoria, respectively. Likewise, unicellular zooflagellates such as Euglenoids, Ciliates (Paramecium, Colpoda) and Rotifers were seen.

Usually, fertilizers are applied in the flooded fields before transplanting the rice. Since inorganic fertilizers take a long time to be decomposed by the microorganisms, the presence of nitrogen, phosphorus and potassium in the water increase the growth of green and blue green algae that supply the food chain of mosquito larvae for their growth and development [4]. In addition, presence of these algae also supports the life of zooflagellates that also add to the water turbidity [7].

\subsection{Rice Canopy Category}

In general, rice canopy category significantly modified the larval density only in conventional farms. Specifically, the number of tillers per plant significantly contributed to the category. Number of tillers per plant serves as plant canopy for resting sites and protection from adverse elements including high temperature, low humidity and heavy winds. After feeding, female mosquitoes seek out resting places. After digesting the blood meal, the adult will oviposit in an appropriate habitat. Washino and Wood [8] studied characteristics of land cover in California which were dominated by low mosquito producing rice fields and high mosquito producing rice field using remote sensing. Probability of females completing the gonotrophic cycle could be estimated by the state of vegetation canopy development of the potential habitat.

\subsection{Other Findings}

Plenty of livestock that grazed around the farms were observed of which, the nearest grazing distance from the perimeter of the rice paddies was 30 meters. These animals were goats, swamp buffaloes, cattle, free range chickens and ducks. Similarly, residents around the farms also engaged in backyard piggeries. Other domestic animals living near the farms were dogs and cats.

The presence of livestock occupying the pastures near the rice paddies provides a dynamic support to Aedes spp. mosquito population. Soon after adult female mosquitoes emerge from the rice fields they will seek sources of blood meal to nourish their eggs after mating [9]. Since livestock is always available anytime as blood meal for these mosquitoes, there will always be eggs laid and larvae maintained until they develop into adults in the water paddies of these farms that have particular characteristics in their microclimate and rice canopy variables that support the life cycle of Aedes spp. mosquitoes [8].

In addition, Aedes spp. mosquitoes are mechanical or biological vectors of a number of diseases affecting animals such as dirofilariasis and fowl pox and a number of zoonotic pathogens that are transmitted to humans from animal reservoirs such as arboviruses causing encephalitis aside from the known human disease such as Dengue. Hence, the presence of livestock adds to the maintenance cycle of pathogens transmitted by Aedes spp. mosquitoes.

\section{Conclusion}

Larval density is a good monitoring index for mosquito density in evaluating environmental indices for integrated vector control. Rice paddies in mixed and conventional farms are better density culture 

Selected Rice Fields of Muňoz, Nueva Ecija

grounds for sustaining larval development than organic farms. The variables were found to be significant contributor in influencing the larval density in mixed and conventional farms: macroclimate category with wind velocity \& ambient temperature variables, microclimate category with water temperature \& water turbidity and rice canopy category with rice height and number of tillers per plant as variables.

For mixed farms, a regression equation model using variables under microclimate category and rice canopy were created to predict larval density. For conventional farms, equation models using variables under the macroclimate, microclimate and rice canopy categories were created to predict larval density. No environmental exposure variables were identified as effect modifiers for larval density in organic farms.

\section{References}

[1] Gubler, D. J., Edward, B., and Hayes, M. D. 1992. "Dengue and Dengue Hemorrhagic Fever.” Accessed May 19, 1992. http:/wonder. Cdc.gov/wonder/prevgid/p0000373.asp.

[2] WHO., Media. Centre. 2002. "Disease Outbreak News. Dengue fever, Dengue hemorrhagic fever." WHO Fact Sheet. Accessed May 19, 2006. http://www.who.int/csr/diseasedengue/en.html.

[3] Falcon, T. 2005. "Water Management in Rice in Asia." Accessed June 2, 2006. http:/www.fao.org/documents.

[4] Belding, D. L. 1964. Textbook of Parasitology. 3rd Edition. New York: Appheton-Century-Cofts, 802, 872, 684.

[5] Chandler, A. C. and C. P. 1961. Introduction to Parasitology 10th Edition. New York: John Wiley and Sons Incorporated. 730, 743, 750.

[6] Rice as a Plant: Growth Phases. 2002. "In Ricepedia, the Online Authority on Rice.” Accessed June 2, 2006. https:ciat.cgiar.org/crops/rice.

[7] Javier, E., and Rodante, T. 2003. "Nitrogen Dynamics in Soils Amended with Different Organic Fertilizers.” Phil. J. Crop Sci. 28 (3): 49-60.

[8] Washino, R. K., and Byron, L. W. 1994. "Application of Remote Sensing to Vector Arthropod Surveillance and Control." American Journal of Tropical Medicine and Hygiene 50: 134-144.

[9] Barrinuevo, G. L., and REY, L. E. 2005. "DOH Warns of Dengue Outbreak.” Accessed May 19, 2006. http://www.manilatimes.net/national/2005/aug/09/yehey/l ife/20050809lif3.html. 